\title{
Seed biostimulant Bacillus sp. MGW9 improves the salt tolerance of maize during seed germination
}

\author{
Heqin $\mathrm{Li}^{1 \dagger}$, Haiwang Yue ${ }^{2 \dagger}$, Li Li ${ }^{3}$, Yu Liu' ${ }^{1}$, Haiyan Zhang ${ }^{1}$, Jianhua Wang ${ }^{3}$ and Xuwen Jiang ${ }^{1,3^{*}}$ (C)
}

\begin{abstract}
Crop performance is seriously affected by high salt concentrations in soils. To develop improved seed pre-sowing treatment technologies, it is crucial to improve the salt tolerance of seed germination. Here, we isolated and identified the strain Bacillus sp. MGW9 and developed the seed biostimulant MGW9. The effects of seed biopriming with the seed biostimulant MGW9 in maize (Zea mays L.) under saline conditions were studied. The results show that the strain Bacillus sp. MGW9 has characteristics such as salt tolerance, nitrogen fixation, phosphorus dissolution, and indole-3-acetic acid production. Seed biopriming with the seed biostimulant MGW9 enhanced the performance of maize during seed germination under salinity stress, improving the germination energy, germination percentage, shoot/seedling length, primary root length, shoot/seedling fresh weight, shoot/seedling dry weight, root fresh weight and root dry weight. Seed biostimulant MGW9 biopriming also alleviated the salinity damage to maize by improving the relative water content, chlorophyll content, proline content, soluble sugar content, root activity, and activities of superoxide dismutase, catalase, peroxidase and ascorbate peroxidase, while decreasing the malondialdehyde content. In particular, the field seedling emergence of maize seeds in saline-alkali soil can be improved by biopriming with the seed biostimulant MGW9. Therefore, maize seed biopriming with the seed biostimulant MGW9 could be an effective approach to overcoming the inhibitory effects of salinity stress and promoting seed germination and seedling growth.
\end{abstract}

Keywords: Salt stress, Seed biostimulant, Seed germination, Zea mays, Bacillus sp

\section{Introduction}

Soil salinization is an increasingly serious agricultural problem in the world. It greatly affects the growth and development of crops, resulting in a significant loss of productivity. As a result of poor irrigation, over-fertilization and desertification processes, cultivated soils around the world have become more saline and alkaline. More than 800 million hectares of land worldwide are currently affected by salt stress (Ramadoss et al. 2013). Maize (Zea mays L.) is an important global cereal crop whose

\footnotetext{
*Correspondence: mjxw888@163.com

${ }^{\dagger}$ Heqin Li and Haiwang Yue contributed equally to this paper

${ }^{1}$ Dryland Technology Key Laboratory of Shandong Province, Qingdao

Agricultural University, Qingdao 266109, China

Full list of author information is available at the end of the article
}

production needs to be increased to meet the food needs of a growing world population (Tilman et al. 2011). Nevertheless, the growth of maize and grain quality can be severely affected by salinity, drought, high temperature and other adverse environmental conditions (Gong et al. 2014). Salt stress is emerging as a particular constraint to global crop production, and it is estimated that it will affect about $20 \%$ of the world's irrigated land and will lead to a loss of up to $50 \%$ of the land by the middle of the twenty-first century (Mahajan and Tuteja 2005; Zhu 2001). Sodium chloride ( $\mathrm{NaCl})$, as the main form of soil salinity, can lead to crop yield reduction or even death by making root water uptake more difficult, and can lead to plant poisoning by accumulating high concentrations of $\mathrm{Na}^{+}$and $\mathrm{Cl}^{-}$in plants (Deinlein et al. 2014; Paul and
Springer Open (c) The Author(s) 2021. This article is licensed under a Creative Commons Attribution 4.0 International License, which permits use, sharing, adaptation, distribution and reproduction in any medium or format, as long as you give appropriate credit to the original author(s) and the source, provide a link to the Creative Commons licence, and indicate if changes were made. The images or other third party material in this article are included in the article's Creative Commons licence, unless indicated otherwise in a credit line to the material. If material is not included in the article's Creative Commons licence and your intended use is not permitted by statutory regulation or exceeds the permitted use, you will need to obtain permission directly from the copyright holder. To view a copy of this licence, visit http://creativeco mmons.org/licenses/by/4.0/. 
Lade 2014; Yu et al. 2020; Zhu 2001). High concentrations of salt lead to a combination of ionic imbalance and hypertonic effects at biochemical and molecular levels (Munns 2002; Tester and Davenport 2003). For example, salt stress leads to chloroplast damage, decreased photosynthetic rate and increased photorespiratory rate, accumulation of reactive oxygen species (ROS), decreased enzyme efficiency and activated SOS gene expression (Hoshida et al. 2000; Teixeira and Pereira 2007; Zhang et al. 2019). However, most plants have developed the ability to reduce the negative effects of salinity through the regulation and compartmentalization of ions, synthesis of compatible solutes, induction of antioxidant enzymes, induction of phytohormones, and alteration of photosynthetic pathways (Rojas-Tapias et al. 2012).

Various methodologies are in vogue for developing stress-tolerant varieties, either through conventional breeding or through transgenic technology. Alternatively, simpler and more economical practices are competing to solve this problem. Seed priming is a farmer-friendly technique recommended by many researchers for better establishment and growth even under adverse conditions (Filippou et al. 2013a; dos Santos Araújo 2021). It is well known that different environmental stresses often activate similar cell signaling pathways and cellular responses, and seed priming can activate these signaling pathways early in growth and lead to faster plant defense responses. Different seed priming methods employed to mitigate stress tolerance as reported by many researchers include: hydropriming, halo- and osmopriming, matrix priming, thermopriming, biopriming, drum priming, priming using growth regulators, nutrient priming and redox priming (Adhikary et al. 2021).

Some progress has been made in seed biopriming, and the growth-promoting ability of microorganisms may be highly specific to certain plant species, cultivars and genotypes (Bashan 1998; Moeinzadeh et al. 2010; dos Santos Araújo 2021). For example, Trichoderma viride and T. harzianum improved the seed germination and vigour of radish (Mukhopadhyay and Pan 2012). Seed biopriming with T. viride enhanced root growth in rice (Sureshrao et al. 2016). Seeds inoculated with Bacillus subtilis and Pseudomonas fluorescens produced a significantly increased in the fresh weight, dry weight, photosynthetic pigments, proline, total free amino acids and crude protein content in radish roots and leaves under salt stress (Mohamed and Gomaa 2012). Regarding seeds inoculated with Hallobacillus sp. SL3 and Bacillus halodenitrificans PU62, the root elongation and dry weight of wheat seedlings under salt stress were increased by more than 90 and $17.4 \%$, respectively, compared with those of uninoculated wheat seedlings (Ramadoss et al. 2013). Under saline conditions, compared to uninoculated plants, inoculation with Pseudomonas putida KT2440 significantly improved seed germination and root and stem length of soybean and corn plants (Costa-Gutierrez et al. 2020). These findings suggest that seed biopriming with different beneficial microorganisms can not only improve seed quality, but also improve seedling vigour and resistance to abiotic stress, thus providing an innovative crop protection tool for the sustainable improvement of crop yields.

In recent years, plant biological stimulants have been developed which can help crops to resist abiotic stress, thus attracting much attention (Akhtar et al. 2008; Porcel et al. 2012; Woo and Pepe 2018). The widely accepted definition of a plant biostimulant is any substance and/or microorganism applied to plants with the aim of enhancing nutrition efficiency, abiotic stress tolerance and/or crop quality traits, regardless of its nutrient content (du Jardin 2015). In recent years, the use of biostimulants to improve crop seed germination and emergence ability under abiotic and biotic stress has attracted much attention (Selvakumar et al. 2017; Costa-Gutierrez et al. 2020; Li et al. 2020; Rafiq et al. 2020). Our purpose was to isolate and identify the salt-tolerant beneficial strains to develop seed biostimulants, and to study the effects of biopriming on the seed germination and seedling emergence of different maize varieties under salt stress by means of a pre-sowing treatment with the probiotics as bio-initiators, so as to provide a basis for the research on improving seed quality.

\section{Materials and methods \\ Isolation and cultivation of strains}

Bacterial strains were isolated from extremely arid soil samples near the Great Wall of the Ming Dynasty in Shandan County of Gansu Province (100.88E, 38.84 N). In August 2017, soil samples were put into sterile sealed bags, taken back to the laboratory and stored at -20 ${ }^{\circ} \mathrm{C}$ for use. After being mixed and grounded, $20 \mathrm{~g}$ of the soil sample was poured into a triangular flask containing $80 \mathrm{~mL}$ of sterile water on a rotating shaker at $180 \mathrm{rpm}$ for $30 \mathrm{~min}$ at room temperature. Then, the supernatant was diluted to $10^{-6}$ after a ten-fold dilution with deionized water. An aliquot of $200 \mu \mathrm{L}$ of each dilution was spread on beef extract peptone agar medium containing 10 different concentrations of $\mathrm{NaCl}(5,7,8,9,10,11,12,13$, 14 and $15 \%(\mathrm{w} / \mathrm{v}))$, with six replicates per concentration. After $72 \mathrm{~h}$ of culture at $28{ }^{\circ} \mathrm{C}$, the colonies with different morphological characteristics were selected and purified on the nutrient agar plate by the plate streaking method. The candidate bacterial strains were numbered into sterile tubes with $25 \%(\mathrm{v} / \mathrm{v})$ glycerol and stored at $-80{ }^{\circ} \mathrm{C}$. 


\section{Screening for salt-tolerance level and growth promoting characteristics of strain MGW9}

To a flask containing $50 \mathrm{~mL}$ of nutrient broth, $\mathrm{NaCl}$ was added to give a final salt concentration of $5,7,8,9,10$, $11,12,13,14$ and $15 \%(\mathrm{w} / \mathrm{v})$. The strains of active growth were then added to each flask and incubated on a rotating shaker at $30{ }^{\circ} \mathrm{C}$ and $180 \mathrm{rpm}$. Bacterial growth was determined as $\mathrm{OD}_{600 \mathrm{~nm}}$ to determine salt tolerance again. In this study, the strain MGW9 and other candidate bacterial strains (data not shown) with a high salt-tolerance level were chosen for further study.

The strain MGW9 was streaked and inoculated into a nitrogen-free culture medium (Liu et al. 2017) containing $12 \% \mathrm{NaCl}$ with three times, and was cultured in a dark incubator at $30{ }^{\circ} \mathrm{C}$ for $4-6$ days. The nitrogen-fixing capacity was detected according to the presence or absence of colonies on a plate.

The strain MGW9 was incubated on bacterial inorganic and organic phosphorus media (Tao et al. 2008) containing $12 \% \mathrm{NaCl}$ with three replicates at $30{ }^{\circ} \mathrm{C}$ for 7 days, respectively. Then, according to the presence of transparent circles, i.e., phosphate-solubilizing circles, if a clear area appeared around the colony, the property of dissolving phosphate was shown. The diameter of the phosphate-solubilizing zone (D) and colony diameter (d) were measured, and the phosphate-solubilizing ability of strain MGW9 was qualitatively tested by $\mathrm{D} / \mathrm{d}$. According to the method described by Li et al. (2019b), the phosphate solubilization index $(\mathrm{PSI})=($ colony diameter + halo zone diameter)/colony diameter.

According to the method of the indole-3-acetic acid (IAA) production test described by Li and Jiang (2017), King's B medium containing $100 \mathrm{mg} / \mathrm{mL}$ L-tryptophan and $12 \% \mathrm{NaCl}$ was used to screen for IAA production. The culture supernatant of the candidate strain was mixed with Salkowski reagent at a ratio of 1:1 (v:v). A pink mixture indicated the generation of IAA and its density was recorded at $\mathrm{OD}_{530 \mathrm{~nm}}$. The concentration of IAA produced was estimated from a standard curve of IAA in the range of $0-100 \mu \mathrm{g} / \mathrm{mL}$.

\section{Identification of strain MGW9}

The strain MGW9 was cultured on beef extract peptone agar medium at $30{ }^{\circ} \mathrm{C}$ for $48 \mathrm{~h}$ at $200 \mathrm{rpm}$ with three replicates, and then its morphological characteristics were observed by microscope. Genomic DNA of the strain MGW9 was extracted by bacterial genomic DNA rapid isolation kit (Sangon Biotech (Shanghai) Co., Ltd., China), and was identified according to the complete $16 \mathrm{~s}$ rDNA sequence using a forward 27F primer (5'-AGAGTTTGA TCCTGGCTCAG-3') and the reverse 1492R primer (5'GGTTACCTTGTTACGACTT-3') for PCR amplification reaction. The PCR products were sequenced by Qingdao Pacino Gene Biotechnology Co., Ltd. Sequence homology of nucleotides was compared using the blast search program. The tightly related sequences were aligned by ClustalW using the MEGA version 5.1 software package, and the phylogenetic tree was constructed by the neighbor joining $(\mathrm{NJ})$ method. The bootstrap replications (1000) were used as statistical support for nodes in the phylogenetic tree.

\section{Seed priming using the seed biostimulant MGW9}

Seeds of hybrid maize 'Zhongdi175' (ZD175), 'Zhengdan958' (ZD958) and 'Denghai605' (DH605) were used. Pure maize seeds were randomly selected from each sample for the following experiments.

(i) Thousand-seed weight (TSW) test: the TSW was measured using 500 seeds in each of the three replicates and then converted to thousand seed weight (Li et al. 2019a).

(ii) Seed moisture content (SMC) test: the seeds were ground and dried at $130 \pm 0.5{ }^{\circ} \mathrm{C}$ for $4 \mathrm{~h}$ and the moisture content basis was calculated from the fresh weight (ISTA 2007).

(iii) Seed water absorption test: 100 maize seeds from each of the three maize varieties were measured for their initial weight, and then soaked in sterile water and taken out every $2 \mathrm{~h}$. After the water on the surfaces of the seeds was wiped off, the seeds were weighed, and then the water absorption of the seeds at different time points was calculated, with three replicates for each variety. Additionally, the water absorption characteristic equation of maize seed was obtained by curve fitting analysis of the average water absorption of three maize seed samples at each time point.

(iv) Preparing SB-MGW9: the strain MGW9 was inoculated into a nutrient broth and cultured in a fermentation tank at a stirring speed of $150 \mathrm{rpm}$, a culture temperature of $28{ }^{\circ} \mathrm{C}$ and a ventilation rate of $1.5 \mathrm{~L} / \mathrm{min}$ for $48-60 \mathrm{~h}$, and the number of the MGW9 was adjusted to be $1.0 \times 10^{8}-1.5 \times 10^{8} \mathrm{cfu} /$ $\mathrm{mL}$, while the $\mathrm{pH}$ value of the bacterial liquid was adjusted to be 7.0-8.0.

(v) Seed priming with SB-MGW9: two-factor randomized block design was used in the experiment. The soaking time, as factor $\mathrm{A}$, was set to two different times: 3 and $6 \mathrm{~h}$. The moisturizing time was factor $\mathrm{B}$, which was divided into two different times: 12 and $24 \mathrm{~h}$. After treatment, the primed seeds were air dried at $25{ }^{\circ} \mathrm{C}$ to near their original moisture contents. Factors A and B were randomly divided into 4 treatments, and the untreated group (no 
priming) was used as the control (C). Treatment 1 (T1) means that the seeds were soaked for $3 \mathrm{~h}$, and moisturized for $12 \mathrm{~h}$; Treatment 2 (T2) means that the seeds were soaked for $3 \mathrm{~h}$, and moisturized for $24 \mathrm{~h}$; Treatment 3 (T3) means that the seeds were soaked for $6 \mathrm{~h}$, and moisturized for $12 \mathrm{~h}$; and treatment 4 (T4) means that the seeds were soaked for $6 \mathrm{~h}$, and moisturized for $24 \mathrm{~h}$.

\section{Germination and seedling growth test}

The pure seeds were randomly selected for the standard germination test. The seed surface was sterilized with $1 \%$ $\mathrm{NaClO}$ (w/v, Beijing Chemical Reagent Company, Beijing, China) for $10 \mathrm{~min}$, then washed three times with distilled water and air dried for use. The seeds were germinated by adopting a rolling paper germination. Firstly, two pieces of germinating paper (Anchor Paper Co., St Paul, MN, USA) were stacked and moistened by $100 \mathrm{mM}$ $\mathrm{NaCl}$ solution, and the redundant water on the paper was removed by a towel. Secondly, the primed seeds were alternately placed on a germination paper bed, with directions of the seed holes being consistent, the paper bed was rolled up and placed into a self-sealing bag, and the seed hole ends were vertically placed into a Versatile Environmental Test Chamber (MGC-350HP, Shanghai Yiheng Technology Instrument Co., Ltd., Shanghai, China) at $25 \pm 0.5{ }^{\circ} \mathrm{C}$ and with an illumination cycle of $12 \mathrm{~h}$ of light and $12 \mathrm{~h}$ of darkness. Each treatment was repeated three times, with 100 seeds per repetition (Jiang et al. 2016). The no priming seeds were used as the control. The germination energy (GE) and germination percentage (GP) were measured on the 4th and 7th days after the experiment was established. GP is the normal seedling number on the 7th day after seed planting (Li et al. 2019a). While counting the GP, 10 seedlings with uniform size were randomly selected to measure six indices, including shoot/seedling length (SL), primary root length (PRL), shoot/seedling fresh weight (SFW), shoot/ seedling dry weight (SDW), root fresh weight (RFW) and root dry weight (RDW). For SDW and RDW, the plant tissue (shoot/seedling or root) was dried at $105 \pm 0.5{ }^{\circ} \mathrm{C}$ for $8 \mathrm{~h}$.

\section{Assay for biochemical index}

After passing through a $2 \mathrm{~mm}$ sieve, the sand was sterilized and placed in plastic pots (volume $150 \mathrm{~mL}$ ), with $100 \mathrm{~g}$ of sterilized sand per pot. The content of deionized water in the sterilized sand was $10 \%(\mathrm{v} / \mathrm{w})$. Salt treatment was carried out by supplementing deionized water with $\mathrm{NaCl}$ at a final concentration of $100 \mathrm{mM}$. After the primed seeds were placed in the sand bed, the pot was sealed with transparent preservative film. No primed seeds were used as the control. There were three replicates for each treatment and 15 seedlings per replicate. The relative water content (RWC) of the leaf samples was determined, expressed as a percentage, referring to the method of Ghahfarokhi et al. (2015). The chlorophyll (Chl) content was measured by a SPAD502 Plus meter. The level of lipid peroxidation was determined by the content of malondialdehyde (MDA), the content of proline was determined by extraction with 3\% 5-sulfosalicylic acid at room temperature, and the content of soluble sugar was measured by the anthrone-sulfuric acid method (Zhu et al. 2010). The root activity was determined by the triphenyltetrazolium chloride (TTC) method (Li et al. 2015). Approximately $500 \mathrm{mg}$ of a fresh leaf sample was homogenized in $10 \mathrm{~mL}$ of $0.05 \mathrm{M}$ phosphate buffer ( $\mathrm{pH} 7.8$ ) solution and centrifuged at $10,000 \times \mathrm{g}$ for $10 \mathrm{~min}$ ( $\mathrm{Li}$ et al. 2019b). The supernatant was then collected and stored at $4{ }^{\circ} \mathrm{C}$ for use. The activities of superoxide dismutase (SOD), catalase (CAT), peroxidase (POD) and ascorbate peroxidase (APX) were measured (Chen and Asada 1992; Ghahfarokhi et al. 2015; Zhu et al. 2010).

\section{Field seedling emergence test}

For field seedling emergence (FSE), the samples were sown in saline-alkali land in the Binzhou (soil salt content was $0.61 \%, \mathrm{pH}$ was 7.7 ), Dongying (soil salt content was $0.54 \%, \mathrm{pH}$ was 7.6 ), and Weifang (soil salt content was $0.56 \%, \mathrm{pH}$ was 7.5 ) experimental bases, Shandong, China, in 2020. In this study, the row spacing, spacing between rows, and length of rows were $0.06,0.06$, and $0.60 \mathrm{~m}$, respectively. The seeds were sown using the single seed sowing method with 10 seeds per row and 10 rows per repetition (continuous row, 100 seeds) in three repetitions. The arrangement of seeds was designed using the method of partition comparison. In June, the field emergence test was completed. FSE was measured at the three-leaf stage of maize. FSE $(\%)=[$ FSE-Binzhou (\%) + FSE-Dongying (\%) + FSE-Weifang (\%)]/3.

\section{Statistical analysis}

Data were analyzed by means of a one-way analysis of variance (ANOVA) using the SAS statistical software package (SAS Institute, 1999), followed by the calculation of the lowest significant differences (LSD). The work was completed in the Seed Science and Engineering Laboratory of Qingdao Agricultural University from March to September 2020.

\section{Results}

Isolation, identification and characteristics of strain MGW9 According to the morphological characteristics, 19 strains of salt-tolerant bacteria were isolated from soil 
samples. Among all of the isolated strains, the strain MGW9 has the maximum salt-tolerance level of $12 \%$ $\mathrm{NaCl}$; furthermore, this strain has growth promoting characteristics. The characteristics of the strain MGW9 cultured under the condition of $12 \% \mathrm{NaCl}$ mainly include the following three aspects: (i) Nitrogen fixation: the strain MGW9 was streaked on nitrogen-free medium and cultured in a dark incubator at $30{ }^{\circ} \mathrm{C}$ for $4-6$ days, and MGW9 colonies were found on the plate. (ii) Phosphorus dissolution: the transparent circle of MGW9 could be observed on the third day after inoculation in the organic phosphate and inorganic phosphate medium, and the size of the transparent circle tended to be stable until the seventh day. When the transparent zone was stable, the ratio of the diameter of dissolving phosphorus zone (D) to the diameter of bacterial colony (d) was 1.7 in organic phosphorus medium and 1.95 in inorganic phosphorus medium. iii) IAA production: the standard curve equation of IAA concentration and absorbance change was $Y=0.025 X+0.001\left(R^{2}=0.985\right.$, $Y$ represents the absorbance, and $\mathrm{X}$ represents the IAA concentration). The IAA production of the strain MGW9 in King's B medium was $19.24 \mathrm{mg} / \mathrm{L}$ (Table 1 ).

A BLAST search and phylogenetic analysis of the National Center for Biotechnology Information (NCBI) data showed that the strain MGW9 had 99.0\% sequence homology with the bacteria WSB-1 (KJ950500.1). Based on its morphology, including Gram-positive staining, the cells being rod-shaped and the 16S rDNA genetic sequence (1424 bp), the strain was named Bacillus sp. MGW9. Its 16S rRNA gene sequence has been deposited in the NCBI GenBank under accession number MW663489. The strain was preserved in the China General Microbiological Culture Collection Center on November 6, 2019; CGMCC No. 18690 (Fig. 1).

\section{The thousand seed weight, seed moisture content and water absorption characteristics of seed samples from three maize varieties}

The thousand seed weight (TSW) and seed moisture content (SMC) of seed samples from three maize varieties were 342.7-361.3 $\mathrm{g}$ and 11.3-11.8\% (lower than the

Table 1 The performance for nitrogen fixation, phosphorus dissolution and indole-3-acetic acid production of the strain MGW9

\begin{tabular}{lll}
\hline Strain & Characteristics & Results \\
\hline MGW9 & Nitrogen fixation (Yes or No) & Yes \\
& Organic phosphorus dissolution & $\mathrm{D} / \mathrm{d}=1.7$ \\
& Inorganic phosphorus dissolution & $\mathrm{D} / \mathrm{d}=1.95$ \\
& IAA production & $19.24 \mathrm{mg} / \mathrm{L}$ \\
\hline
\end{tabular}

safe water content $13 \%)$, respectively. The water absorption curve equation of maize seed was $\mathrm{Y}=\mathrm{K}(6.519 \mathrm{X}-$ $0.224 \mathrm{X}^{2}+2.879$ ), where $\mathrm{K}$ is the coefficient of variation. In the seed imbibition stage, the water absorption rate of the seed samples of three varieties showed a trend of first fast and then slow change, and the change became stable after $12 \mathrm{~h}$ (Fig. 2).

\section{Effects of seed biopriming with biostimulant MGW9 on maize seed germination under normal and saline conditions}

Compared to normal conditions, the germination energy (GE) and germination percentage (GP) of three maize varieties sample seeds were significantly decreased under salt stress, the GE of ZD175, ZD958 and DH605 decreased by $5,20.5$ and $14.5 \%$, respectively, and the GP of ZD175, ZD958 and DH605 decreased by 10, 11.6 and $8.5 \%$, respectively. Compared with the control, the GE and GP of seeds after priming treatments were higher, and the priming effects were different under different germination environments. In the normal germination environment, except for ZD958, the GE and GP of ZD175 and DH605 sample seeds after biopriming were not significantly different from the control $(P<0.05)$. Additionally, there was no significant difference in the GE among different priming treatments of the same variety, and the GP was the same (Fig. 3a, b). This may be related to the fact that the priming effect was not obvious when the initial level of seed vigour of the sample was high. Under salinity stress, the GE and GP of seeds after priming treatments were significantly higher than that of the control $(P<0.05)$, except for the GP of ZD175-T1, and the priming effects of different priming treatments were different (Fig. 3c, d). Comprehensively analyzing the GE and GP of different priming treatments, the results show that T3 had the best seed biopriming effect (Fig. 3).

\section{Effects of seed biopriming with biostimulant MGW9 on maize seedling growth under salinity stress condition} Under salinity stress, the six seedling growth indices after seed biopriming were higher than the control. The suitable seed biopriming treatment with SB-MGW9 was different from different varieties. The suitable treatments of ZD175 were T2 and T3, those of ZD958 were T3 and T4, and those of DH605 were T2 and T3 (Table 2). According to comprehensive consideration of the six indices of seedling growth, the most suitable treatment for the three maize varieties was T3. Compared with the control, the shoot/seedling length (SL), primary root length (PRL), shoot/seedling fresh weight (SFW), root fresh weight (RFW), shoot dry weight (SDW), root dry weight (RDW) of ZD175 increased by 49.3, 50.7, 58.0, 70.0, 61.1 and $61.5 \%$, respectively, ZD958 increased by 49.2 , 
a

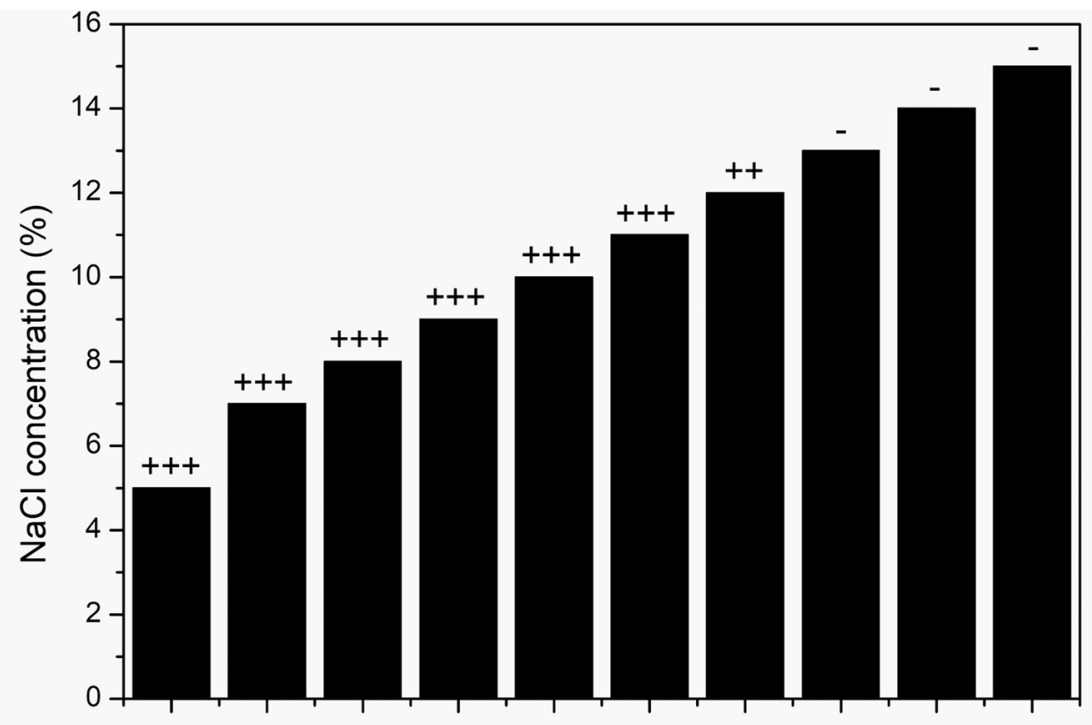

MGW9

b

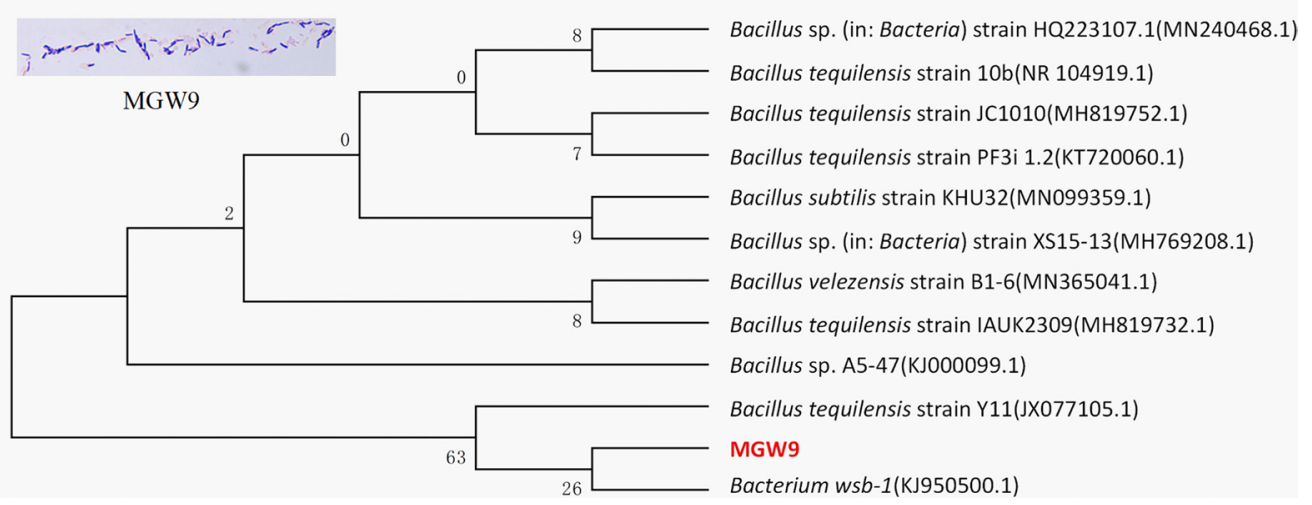

Fig. 1 Identification and characteristics of the strain MGW9. a the salt-tolerance level of the strain MGW9 (From ' +++ ' to' + 'indicates the salt tolerance ability from strong to weak; '-'indicates no such ability.); $\mathbf{b}$ the morphology and phylogenetic tree of the strain MGW9

49.2, 35.0, 25.0, 57.3 and 83.3\%, respectively, and DH605 increased by $44.1,46.5,60.0,62.5,48.9$ and $61.5 \%$, respectively (Table 2).

\section{Effects of seed biopriming with biostimulant MGW9} on the relative water content, chlorophyll content, malondialdehyde content, proline content, soluble sugar content and root activity of maize seedlings under salinity stress

Under salinity stress, compared with the control, the relative water content (RWC), chlorophyll (Chl) content, proline content, soluble sugar content and root activity of the seedlings of the three maize varieties after seed biopriming were significantly increased except for the malondialdehyde (MDA) content $(P<0.05)$. After comparative analysis of the data of the six biochemical indices, it can be seen that the different seed biopriming treatments have different effects. According to the content of MDA, the suitable seed biopriming treatments were $\mathrm{T} 3$ and $\mathrm{T} 4$, but there was no significant difference between T3 and T4. Additionally, regarding the other five indices, the suitable seed biopriming treatments for the three maize varieties were $\mathrm{T} 2$ and $\mathrm{T} 3$, and there was also no significant difference between T2 and T3. According to comprehensive consideration of the six biochemical indices data, the suitable seed biopriming treatment for the three maize varieties was T3. Compared with the control, the RWC, 


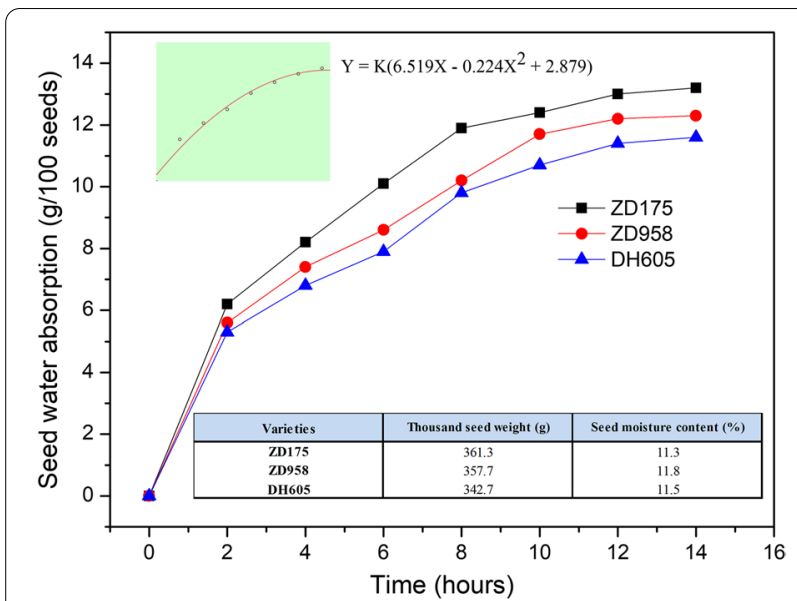

Fig. 2 The initial indices and water absorption characteristics of maize seed samples

Chl, proline, soluble sugar content and root activity of ZD175-T3 increased by $9.1,12.3,49.1,37.2$ and $25.0 \%$, respectively, and those of ZD958-T3 increased by 7.3, 9.3, 59.9, 29.4 and $15.9 \%$, respectively, and those of DH605-T3 increased by 5.0, 12.3, 56.9, 24.0 and 14.3\%, respectively. In addition, the MDA content in seedlings of ZD175-T3, ZD958-T3 and DH605-T3 decreased by $32.2,24.3$ and $29.4 \%$, respectively (Fig. 4).

\section{Effects of seed biopriming with biostimulant MGW9 on the superoxide dismutase, catalase, peroxidase and ascorbate peroxidase activities of maize seedlings under salinity stress}

Compared with the control, the activities of superoxide dismutase (SOD), catalase (CAT), peroxidase (POD) and ascorbate peroxidase (APX) in maize seedlings increased significantly after seed biopriming with SB-MGW9 $(P<0.05)$. According to comprehensive analysis of the four sets of enzyme activity data, the different seed biopriming treatments had different priming effects. The suitable seed biopriming treatments for the three maize varieties were $\mathrm{T} 2$ and $\mathrm{T} 3$, and there were no significant differences in the four enzyme activity indices between T2 and T3. The most suitable treatments for the different maize varieties were $\mathrm{T} 3$ for ZD175 and DH605, and T2 for ZD958. Compared with the control, the SOD, CAT, POD and APX activities of ZD175-T3 were increased by 42.1, 23.4, 36.1 and 63.9\%, respectively; the SOD, CAT, POD and APX activities of ZD958-T2 were increased by 26.8, 19.6, 43.9 and $94.9 \%$, respectively; and the SOD, CAT, POD and APX activities of DH605-T3 were increased by 47.0, 20.7, 33.5 and 27.2\%, respectively (Fig. 5).
Effects of seed biopriming with biostimulant MGW9 on the saline-alkali field seedling emergence of maize The results show that the field seedling emergence (FSE) of maize seeds after biopriming treatment increased significantly compared with the control $(P<0.05)$, and different maize varieties and biopriming treatments had different effects. According to the results of BinzhouFSE, the suitable seed biopriming treatments for ZD175 were T3 and T4, while those for ZD958 and DH605 were T2 and T3; The suitable seed biopriming treatments were T2 and T3 for ZD175, and T3 and T4 for ZD958 and DH605 according to the results of Dongying-FSE; and the results of Weifang-FSE showed that the suitable seed biopriming treatments of ZD175 and DH605 were T2 and T3, while those for ZD958 were T3 and T4. According to the results of the FSE, which is the average of FSE-Binzhou, FSE-Dongying and FSE-Weifang, the suitable seed biopriming treatments for ZD175 and ZD958 were T3 and T4, and for DH605 they were T2 and T3. Comprehensively considering the results of these indices, the most suitable seed biopriming treatment for the three maize varieties was T3. Compared to the control, FSE-ZD175-T3, FSE-ZD958-T3 and FSE-DH605-T3 increased by 8.2, 8.9 and 6.7\%, respectively (Fig. 6).

\section{Discussion}

Soil salinity is an increasingly serious global problem, as salt hampers plant growth and development and reduces crop yield. Seed germination and early seedling growth are critical stages in plant establishment and production and are very sensitive to salt stress. The harmful effects of $\mathrm{NaCl}$ on seed germination and seedling emergence are caused by the decrease in water use efficiency and nutrient supplement ability when sodium accumulates in soil and the toxic effects of sodium and chloride ions on plants occur (Parida and Das 2005; Munns and Tester 2008; Deinlein et al. 2014; van Zelm et al. 2020). This study indicated that $100 \mathrm{mM} \mathrm{NaCl}$ solution had an obvious salt stress effect on the seed germination and seedling growth of three maize varieties, ZD175, ZD958 and DH605. The germination energy (GE) and germination percentage (GP) of the seeds under salt stress conditions are, respectively, reduced by $12.4-20.5$ and $8.5-11.6 \%$ compared with the control (no stress). Therefore, it is of great practical significance for agricultural production to study the technical methods of improving seed vigour under salt stress in order to alleviate the adverse effects of salt stress on seed germination and seedling emergence.

Various methods have been used to improve crop resistance to stress, including conventional breeding methods such as selective hybridization, mutation breeding, polyploid breeding, genetic engineering etc. (Jisha 

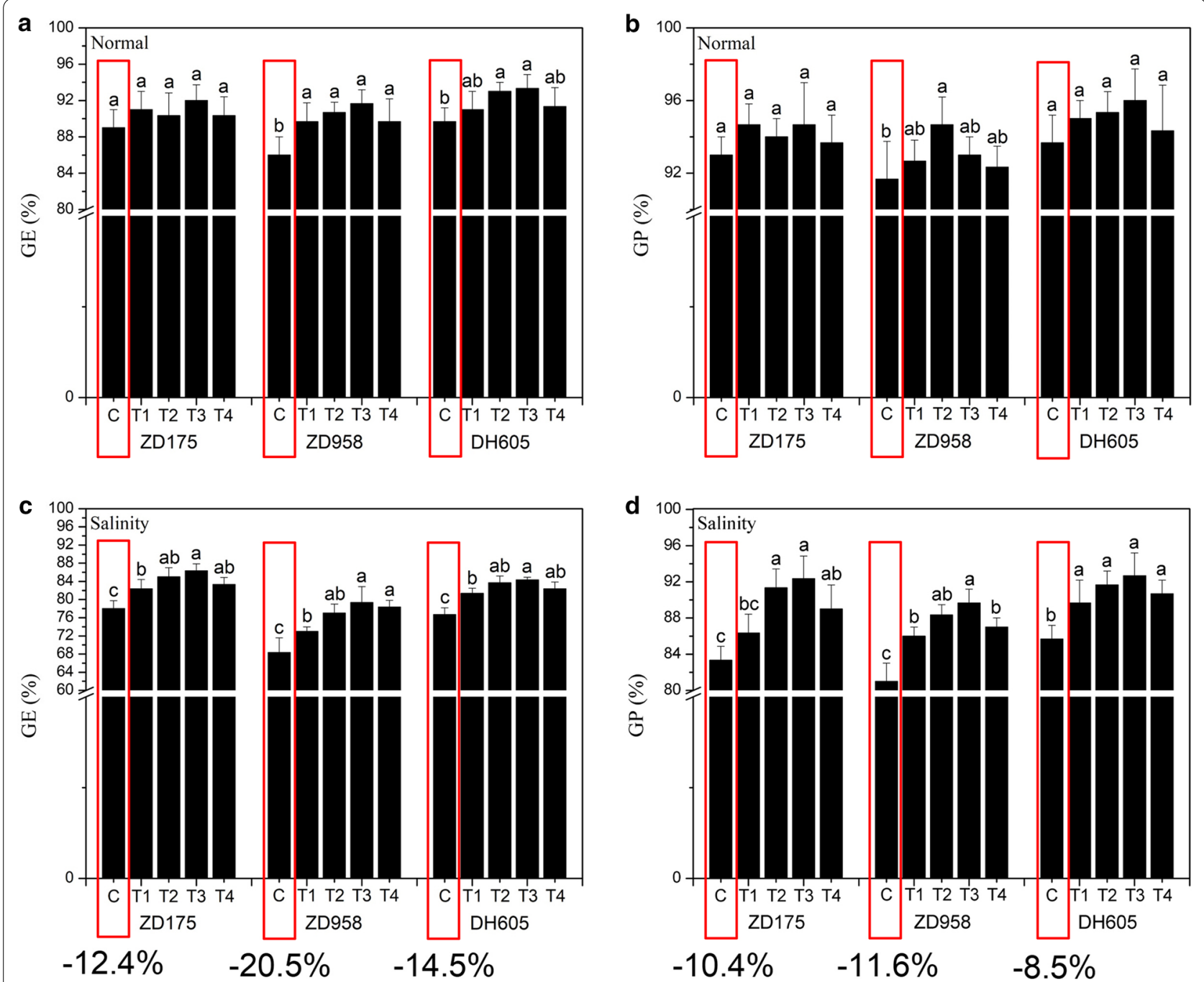

Fig. 3 Effects of the seed biopriming with SB-MGW9 on maize seed germination under normal and saline conditions. The values represent the average of the data obtained in the experiment $(n=3)$. There was significant difference between treatments with different letters $(P<0.05)$. $G E$ germination energy, GP germination percentage

and Puthur 2016), but seed priming as a simple, economical and effective method is more popular with farmers, as it can stimulate seed germination, enhance morphological parameters, and improve plant growth and development under abiotic stress (Jisha et al. 2013; Rhaman et al. 2020a, 2020b). For instance, dos Santos Araújo et al. (2021) suggested that seed priming with $\mathrm{H}_{2} \mathrm{O}_{2}$ can improve the salt tolerance of maize plants by protecting the chloroplast ultrastructure and regulating primary metabolites. In addition, seed priming has been reported to improve the salt tolerance of maize (Li and Jiang 2017), wheat (Ali et al. 2017), cucumber (Maach et al. 2021), camelina (Huang et al. 2021) and other crops.

A recent trend in sustainable development is the use of beneficial microorganisms to increase the nutrient use efficiency of field crops without compromising soil health (Meena et al. 2017). Biopriming is an emerging and promising seed and/or seedling treatment tool for inducing systemic resistance to abiotic and biotic stresses in treated crop. It is a process of biological treatment of seeds that involves combining seed hydration and inoculation with beneficial organisms to protect seeds (Rakshit et al. 2015). In most cases, microbial inoculants such as rhizospheric or endophytic microorganisms (bacteria or fungi) that promote plant growth are used (Ogireddy et al. 2019; Rakshit et al. 2015). As with other seed priming techniques, this technique has proven to be of paramount importance in improving seed quality and performance, as well as plant growth (Aliye et al. 2008; Rajkumar et al. 2010, 2012). 
Table 2 Effects of the seed biopriming with SB-MGW9 on the shoot/seedling length, primary root length, shoot/seedling fresh weight, shoot dry weight, root fresh weight and root dry weight in maize under salinity stress

\begin{tabular}{|c|c|c|c|c|c|c|c|}
\hline Varieties & Treatments & $\begin{array}{l}\mathrm{SL} \\
(\mathrm{cm})\end{array}$ & $\begin{array}{l}\text { PRL } \\
(\mathrm{cm})\end{array}$ & $\begin{array}{l}\text { SFW } \\
(g / 10 S)\end{array}$ & $\begin{array}{l}\text { SDW } \\
(g / 10 S)\end{array}$ & $\begin{array}{l}\text { RFW } \\
\text { (g/10S) }\end{array}$ & $\begin{array}{l}\text { RDW } \\
\text { (g/10S) }\end{array}$ \\
\hline \multirow[t]{5}{*}{ ZD175 } & $C$ & $2.21 \pm 0.02 d$ & $5.06 \pm 0.13 c$ & $1.00 \pm 0.01 c$ & $0.10 \pm 0.02 b$ & $0.95 \pm 0.06 c$ & $0.13 \pm 0.01 c$ \\
\hline & $\mathrm{T} 1$ & $2.88 \pm 0.10 b$ & $6.90 \pm 0.62 b$ & $1.37 \pm 0.07 b$ & $0.13 \pm 0.02 \mathrm{ab}$ & $1.24 \pm 0.13 b$ & $0.17 \pm 0.01 b$ \\
\hline & $\mathrm{T} 2$ & $3.05 \pm 0.08 b$ & $7.85 \pm 0.60 a$ & $1.46 \pm 0.16 a b$ & $0.16 \pm 0.03 a$ & $1.40 \pm 0.07 a b$ & $0.21 \pm 0.02 \mathrm{a}$ \\
\hline & T3 & $3.30 \pm 0.14 a$ & $8.08 \pm 0.53 a$ & $1.58 \pm 0.12 \mathrm{a}$ & $0.17 \pm 0.04 a$ & $1.53 \pm 0.12 \mathrm{a}$ & $0.21 \pm 0.02 \mathrm{a}$ \\
\hline & T4 & $2.67 \pm 0.11 c$ & $7.48 \pm 0.51 \mathrm{ab}$ & $1.28 \pm 0.14 b$ & $0.15 \pm 0.01 a$ & $1.32 \pm 0.12 b$ & $0.20 \pm 0.01 a$ \\
\hline \multirow[t]{5}{*}{ ZD958 } & C & $1.93 \pm 0.14 c$ & $5.11 \pm 0.10 d$ & $0.80 \pm 0.08 d$ & $0.08 \pm 0.01 c$ & $0.82 \pm 0.12 c$ & $0.12 \pm 0.01 d$ \\
\hline & $\mathrm{T} 1$ & $2.38 \pm 0.19 a b$ & $6.65 \pm 0.36 c$ & $1.01 \pm 0.03 c$ & $0.09 \pm 0.02 b c$ & $1.13 \pm 0.06 a b$ & $0.16 \pm 0.02 c$ \\
\hline & $\mathrm{T} 2$ & $2.21 \pm 0.07 b c$ & $7.22 \pm 0.17 b$ & $1.15 \pm 0.04 b$ & $0.11 \pm 0.01 \mathrm{ab}$ & $1.07 \pm 0.05 b$ & $0.18 \pm 0.02 b c$ \\
\hline & T3 & $2.73 \pm 0.34 a$ & $7.73 \pm 0.05 a$ & $1.08 \pm 0.06 b c$ & $0.10 \pm 0.002 \mathrm{ab}$ & $1.29 \pm 0.18 a$ & $0.22 \pm 0.01 a$ \\
\hline & $\mathrm{T} 4$ & $2.52 \pm 0.25 \mathrm{ab}$ & $7.58 \pm 0.51 \mathrm{ab}$ & $1.29 \pm 0.04 a$ & $0.12 \pm 0.004 a$ & $1.22 \pm 0.07 a b$ & $0.19 \pm 0.02 \mathrm{ab}$ \\
\hline \multirow[t]{5}{*}{ DH605 } & C & $1.98 \pm 0.16 c$ & $4.54 \pm 0.15 d$ & $0.90 \pm 0.03 d$ & $0.08 \pm 0.01 c$ & $0.92 \pm 0.07 b$ & $0.13 \pm 0.01 d$ \\
\hline & $\mathrm{T} 1$ & $2.27 \pm 0.31 b c$ & $5.85 \pm 0.19 c$ & $1.14 \pm 0.04 c$ & $0.10 \pm 0.03 b c$ & $1.26 \pm 0.14 a$ & $0.18 \pm 0.02 c$ \\
\hline & $\mathrm{T} 2$ & $2.59 \pm 0.23 a b$ & $6.90 \pm 0.22 a$ & $1.30 \pm 0.10 b$ & $0.12 \pm 0.002 \mathrm{ab}$ & $1.45 \pm 0.24 a$ & $0.23 \pm 0.01 a$ \\
\hline & T3 & $2.68 \pm 0.17 a$ & $6.65 \pm 0.32 b$ & $1.44 \pm 0.14 a$ & $0.13 \pm 0.01 a$ & $1.37 \pm 0.28 a$ & $0.21 \pm 0.02 \mathrm{ab}$ \\
\hline & T4 & $2.45 \pm 0.10 \mathrm{ab}$ & $6.34 \pm 0.23 b$ & $1.22 \pm 0.01 b c$ & $0.12 \pm 0.004 a b$ & $1.21 \pm 0.05 a b$ & $0.20 \pm 0.01 b c$ \\
\hline
\end{tabular}

According to Duncan's multiple range test, different letters in the same column indicate significant differences between treatments at the 0.05 level

$S L$ shoot/seedling length, $P R L$ primary root length, SFW shoot/seedling fresh weight, $R F W$ root fresh weight, SDW shoot dry weight, $R D W$ root dry weight, $S$ seedling (s)

Plant biological stimulants are a new concept put forward in recent years. They are applied to plants for the purpose of enhancing nutritional efficiency, abiotic stress tolerance and/or crop quality traits, irrespective of their nutritional content. By definition (du Jardin 2015), beneficial microorganisms are one of the most important sources for the development of plant biostimulant products. Regarding beneficial fungi, some have been extensively studied and used for their biopesticidal and biocontrol (inducer of disease resistance) abilities and have been exploited by the biotechnology industry as sources of enzymes (Mukherjee et al. 2012; Nicolás et al. 2014). Many plant responses have been demonstrated to be fungus induced, including abiotic stress tolerance, high nutrient use efficiency and high plant growth performance (Colla et al. 2015; Shoresh et al. 2010). Based on the effects, these fungi can be considered as biostimulants. Regarding beneficial bacteria, they can interact with plants in all possible ways. There are two main types of symbiotic endosymbionts and symbiotic rhizospheric plant growth-promoting rhizobacteria (PGPRs) when they are used as biostimulants. PGPRs are multifunctional, affecting all aspects of plant life, including nutrition and growth, morphogenesis and development, responses to biotic and abiotic stresses, and interactions with other organisms in agroecosystems (Babalola 2010; Berendsen et al. 2012; Berg et al. 2014; Bhattacharyya and Jha 2012; Philippot et al. 2013). Some of these functions are usually performed by the same organism, some are strain-specific, and others depend on synergy in the bacterial community. At present, the useful of plant biostimulants to improve seed germination and seed vigour has become a research hotspot. Therefore, in this study, Bacillus sp. MGW9 was isolated and purified from extremely arid soil samples by salt-tolerant screening and morphological and molecular identification. Based on the characteristics of salt tolerance, nitrogen fixation, phosphorus solubilization and indole-3-acetic acid (IAA) production of Bacillus sp. MGW9, the strain was used to develop the seed biostimulant MGW9 (SB-MGW9).

The objective of this study was to investigate the effects of SB-MGW9 biopriming on the seed germination and seedling growth of maize under salt stress. Related reports have shown that some microorganisms could improve the growth performance of plants under a stress environment by providing plant hormones, soluble phosphate, fixed nitrogen, and other substances (Hayat et al. 2010; Ji et al. 2014), and the characteristics of the strains are similar to Bacillus sp. MGW9. Some researchers began to pay attention to the application of microorganisms in seed pre-sowing treatment because of the ability of beneficial microorganisms to inhibit diseases and improve crop germination ability and vitality. We set up four seed biopriming treatments according to the water absorption characteristics of maize seeds (Fig. 2), including seed soaking time and moisturizing time. The results of the germination test show that the germination energy (GE) and germination percentage (GP) of three 

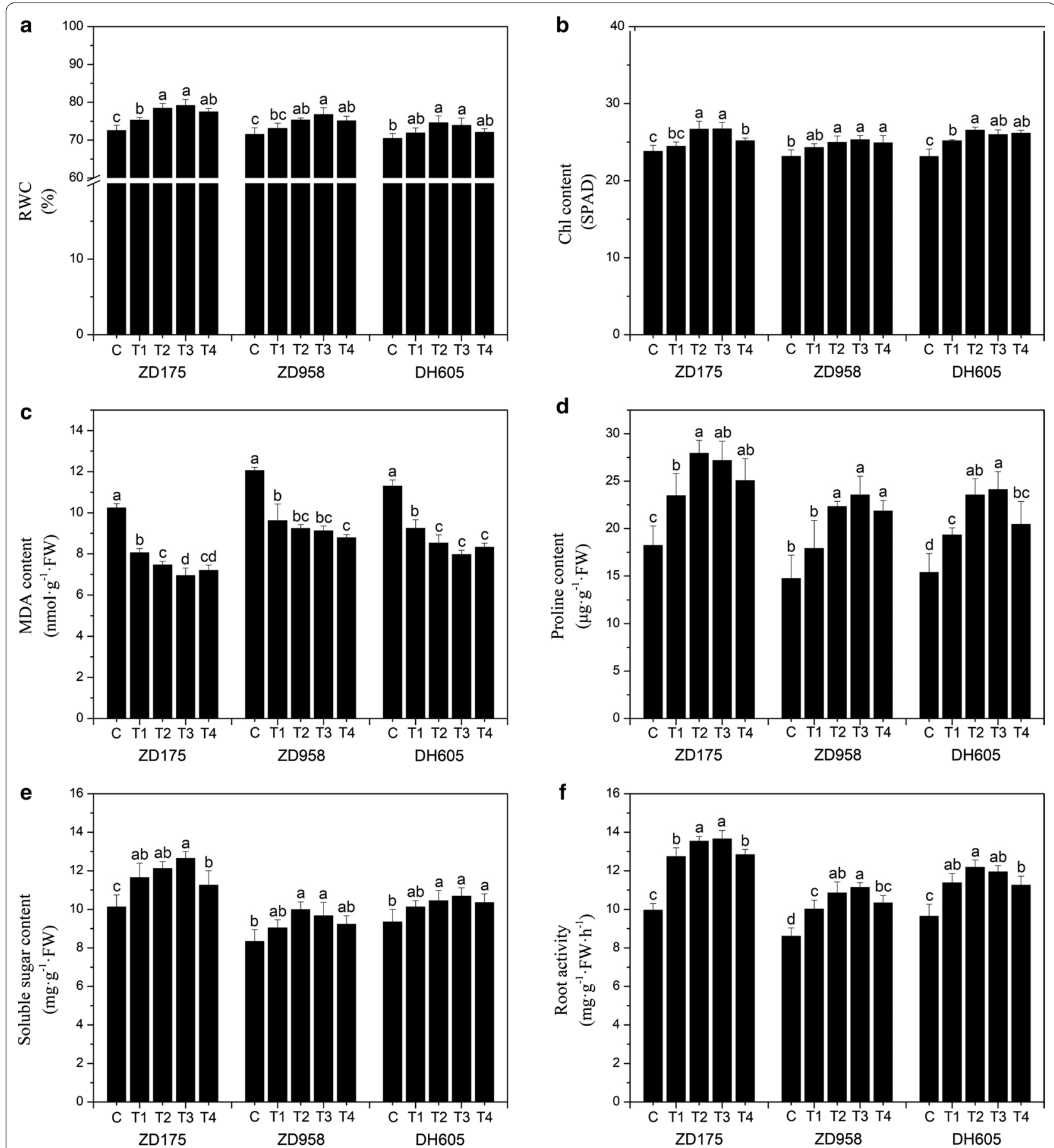

Fig. 4 Effects of the seed biopriming with SB-MGW9 on the relative water content, chlorophyll content, malondialdehyde content, proline content, soluble sugar content and root activity in maize under saline conditions. The values represent the average of the data obtained in the experiment $(\mathrm{n}=3)$. There was significant difference between treatments with different letters $(P<0.05)$. RWC relative water content, Ch/ chlorophyll, MDA malondialdehyde

maize varieties under normal and salt stress conditions were increased after seed biopriming treatment (Fig. 3), but the GE and GP of the seed biopriming treatments of ZD175 and the GP of seed biopriming treatments of DH605 were not significantly different from the control under normal conditions (Fig. 3a). However, under saline 

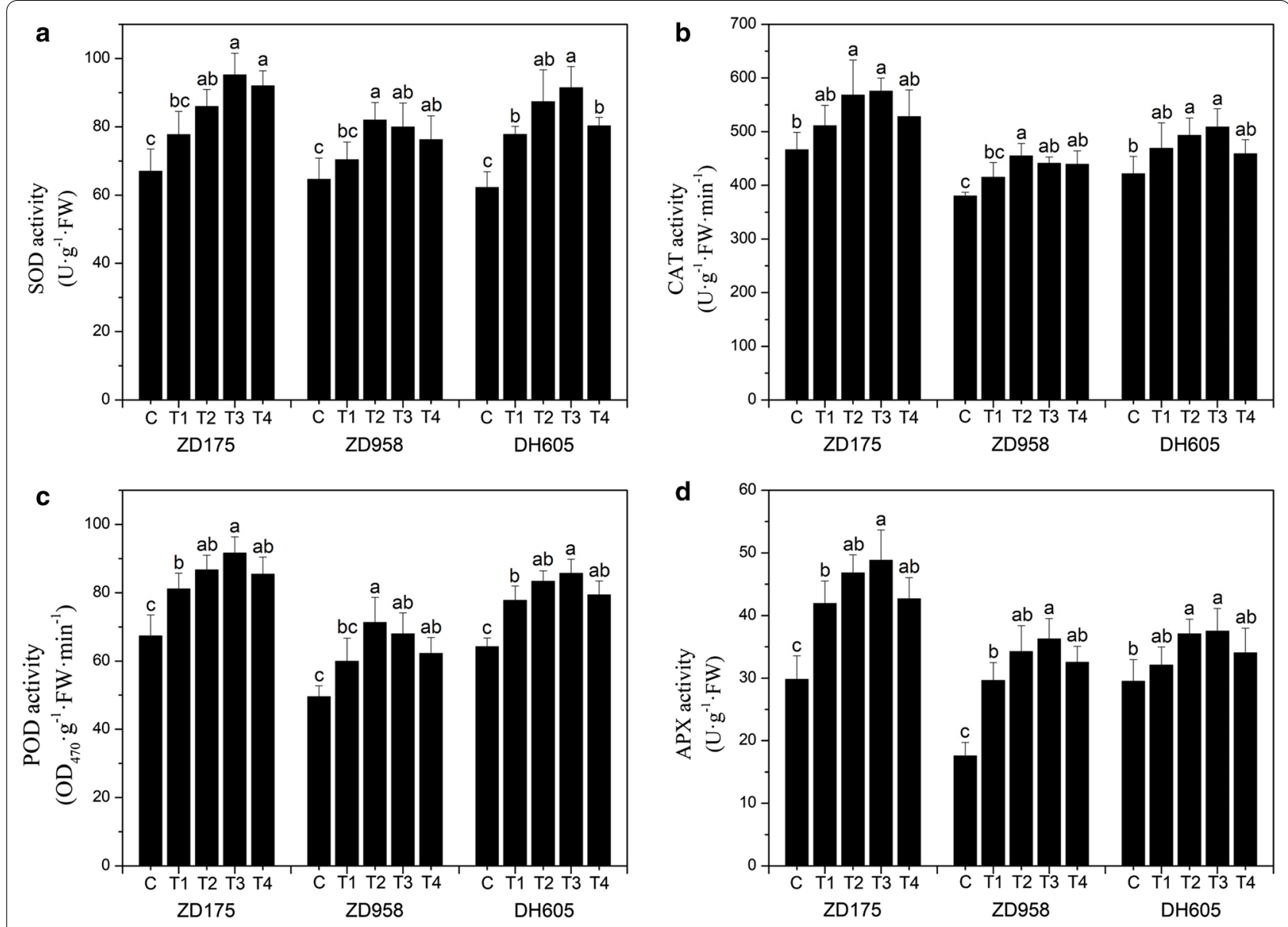

Fig. 5 Effects of the seed biopriming with SB-MGW9 on the superoxide dismutase, catalase, peroxidase and ascorbate peroxidase activities in maize under saline conditions. The values represent the average of the data obtained in the experiment $(n=3)$. There was significant difference between treatments with different letters $(P<0.05)$. SOD superoxide dismutase, $C A T$ catalase, $P O D$ peroxidase, $A P X$ ascorbate peroxidase, $U$ active unit, FW fresh weight

condition, the GE and GP of T2, T3 and T4 of ZD175 and those of the four seed biopriming treatments of ZD958 and DH605 were significantly higher than that of the control $(P<0.05)$ (Fig. 3b). Our results show that SB-MGW9 biopriming could improve the GE and GP of maize seeds under $\mathrm{NaCl}$ stress, and if the initial level of seed vigour is high and the seeds germinate under normal conditions, the effects of SB-MGW9 biopriming may not be significant. This may be due to the earlier completion of metabolic activities before germination in the priming process (dos Santos Araújo et al. 2021; Panuccio et al. 2018), and this advantage of priming seeds leads to the improvement of seed germination and seedling growth.

Salt stress often induces the increase in reactive oxygen species (ROS), hydrogen peroxide $\left(\mathrm{H}_{2} \mathrm{O}_{2}\right)$, superoxide anions $\left(\mathrm{O}^{2-}\right)$ and hydroxyl radicals $(\cdot \mathrm{OH})$ in plants, resulting in oxidative damage to plants (Hyodo et al., 2017). Malondialdehyde (MDA) is a kind of lipid peroxidation product, which is considered to be one of the important indices of oxidative damage to cell membrane caused by ROS (Parida and Das 2005). Our results show that salt stress induced an increase in MDA content in maize seedlings, suggesting that the presence of salt stress may enhance membrane lipid peroxidation, leading to increased membrane permeability, electrolyte extravasation, and ultimately damage to the cell membrane system. However, ZD175-T3, ZD958-T4 and DH605-T3 significantly decreased by $32.2,27.1$ and $29.4 \%$, respectively, compared to non-bioprimed seeds (Fig. 4c). This indicated that maize seedlings had stronger tolerance to oxidative stress after seed biopriming with SB-MGW9. This is similar to the result showing that the content of MDA in mycorrhizal inoculated maize plants is lower than that in non-mycorrhizal plants under temperature stress (Zhu et al. 2010). In addition, proline is a good osmotic agent and radical scavenger to stabilize subcellular structure, which can quench single $\mathrm{O}^{2-}$ or directly react with $\mathrm{OH}$ (Filippou et al. 2013b). Under stress conditions, proline 

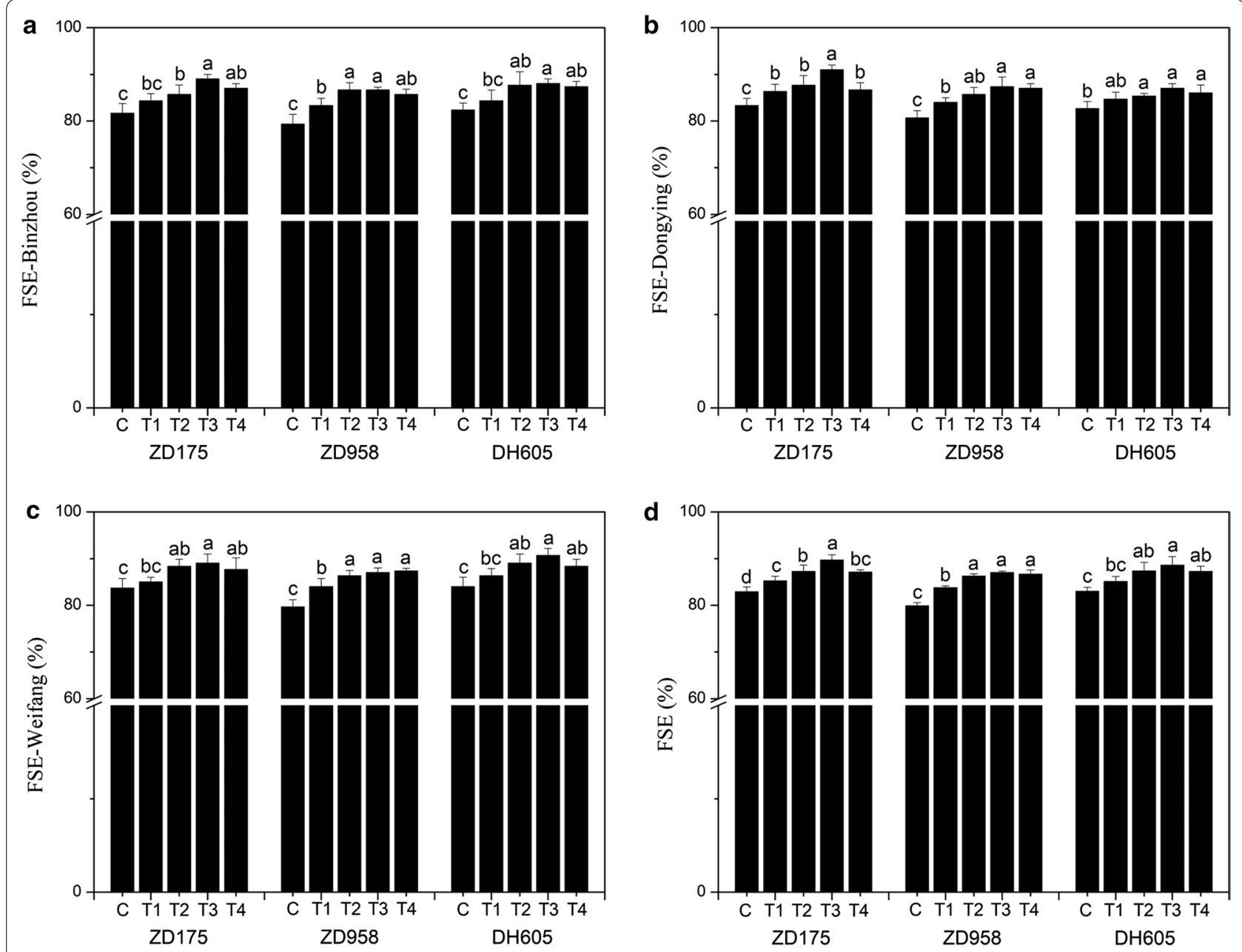

Fig. 6 Effects of the seed biopriming with SB-MGW9 on the saline-alkali field seedling emergence of maize. The values represent the average of the data obtained in the experiment $(n=3)$. There was significant difference between treatments with different letters $(P<0.05)$. FSE field seedling emergence, FSE (\%) [FSE-Binzhou (\%) + FSE-Dongying (\%) + FSE-Weifang (\%)]/3

accumulation may be due to increased synthesis and decreased degradation, which helps to maintain cell water status and protect cell membranes and proteins (Kishor and Sreenivasulu 2014). Bano and Fatima (2009) showed that microorganisms (Rhizobium and Pseudomonas) introduced in the rhizosphere can improve the water use efficiency of maize plants, induce the synthesis of osmotic regulators such as proline, and help maintain the integrity of cell membranes. This is consistent with the results of this study under salt stress, the proline content of biopriming maize seedlings was significantly higher than that of non-biopriming seedlings (Fig. 4d).

In plants, carbohydrate metabolism is involved in key processes in response to abiotic stresses, with key roles in carbon storage, osmotic homeostasis, osmoprotectants and free radical scavenging (Gangola and Ramadoss 2018). Soluble sugars are important osmolytes in plant cells, and their accumulation contributes to the regulation of osmotic stress in plant cells and results in the preservation of biomolecules and membranes (Bohnert and Sheveleva 1998). Gandonou et al. (2012) reported a significant increase in soluble sugar content in sugarcane leaves and roots under salt stress. Borrelli et al. (2018) showed that carbohydrate stores in wheat plants under salt stress are quickly mobilized, releasing soluble sugars that act as compatible solutes under stress. In this work, our results show that the soluble sugar content increased significantly after seed biopriming with SB-MGW9, which could help to alleviate osmotic stress (Fig. 4e). Similar results were observed by Feng et al. (2002), who found that the colonization of arbuscular mycorrhizal fungi could significantly increase the soluble sugar content of salt-treated maize seedlings, indicating that these plants have a higher osmotic adjustment capacity. Additionally, dos Santos Araújo et al. (2021) showed that $\mathrm{H}_{2} \mathrm{O}_{2}$ priming 
could increase the contents of six sugars and polyols in maize plants under salt stress to alleviate osmotic stress.

In addition, plants have evolved a series of defensive measures, including the use of their own antioxidant enzymes and non-antioxidant metabolites to eliminate ROS (Feng et al. 2002). The common antioxidant enzymes include SOD, POD, CAT and APX, which play an important role in the process of scavenging ROS. SOD catalyzes the conversion of $\mathrm{O}^{2-}$ to $\mathrm{H}_{2} \mathrm{O}_{2}$ and $\mathrm{O}_{2}$, while POD and CAT can scavenge $\mathrm{H}_{2} \mathrm{O}$. Additionally, APX can protect chloroplasts and other cellular components from $\mathrm{H}_{2} \mathrm{O}_{2}$ and hydroxyl damage. Some studies have found that under abiotic stress, inoculation of some beneficial bacteria (such as Bacillus subtilis SU47, Glomus etunicatum) can improve plant antioxidant enzyme activity to alleviate the negative effects of stress on plant growth (Upadhyay et al. 2011; Zhu et al. 2010). In our study, compared with non-bioprimed seeds, the activities of SOD, POD, CAT and APX in maize seedlings were significantly increased after biopriming treatment $(P<0.05)$, indicating that SB-MGW9 biopriming could improve the antioxidant defense capacity of maize seedlings under salt stress (Fig. 5).

In summary, based on the results of the RWC, the content of chlorophyll, proline, soluble sugar and malondialdehyde, root activity, field seedling emergence and the activities of superoxide dismutase, catalase, peroxidase and ascorbate peroxidase, the suitable biopriming treatments of SB-MGW9 for the three maize varieties were $\mathrm{T} 2$ (the seeds soaked with biostimulant for $3 \mathrm{~h}$, and moisturized for $24 \mathrm{~h}$ ) and T3 (the seeds soaked with biostimulant for $6 \mathrm{~h}$, and moisturized for $12 \mathrm{~h}$ ). SB-MGW9 could be a promising technique for decreasing the deleterious effects of salt stress for maize seed germination and seedling.

\section{Acknowledgements}

The authors are grateful to Professor Yanming Zhao of Qingdao Agricultural University for helping us to get soil samples in Gansu Province.

\section{Authors' contributions}

$H L, H Y$ and $Y L$ performed the experiment, analyzed the data and wrote the draft. $\mathrm{HZ}$ and LL provided important research assistance to this study. JW and $\mathrm{XJ}$ designed the research and made revision for the manuscript. All authors read and approved the final manuscript.

\footnotetext{
Funding

This research was supported by the National Key Research and Development Program of China (2017YFD0701203, 2017YFD0101202, 2018YFD0300604, 2019YFE0120400), National Natural Science Foundation of China (31601386, 31671621), Special Fund for Agro-scientific Research in the Public Interest (201303002), National System (Maize) of Modern Industrial Technology (nycytx-02), Project of Shandong Province Higher Educational Science and Technology Program (J18KA121).
}

Availability of data and materials

The authors declare that all the data and materials used in this study are available.

\section{Declarations}

Ethics approval and consent to participate

This article does not contain any studies with human participants or animals performed by any of the authors.

\section{Consent for publication}

All authors agree with the contents of the manuscript and its submission to the journal.

\section{Competing interests}

The authors declare that they have no competing interests.

\section{Author details}

${ }^{1}$ Dryland Technology Key Laboratory of Shandong Province, Qingdao Agricultural University, Qingdao 266109, China. ${ }^{2}$ Dryland Farming Institute, Hebei Academy of Agriculture and Forestry Sciences, Hengshui 053000, China. ${ }^{3}$ Seed Science and Technology Research Center, China Agricultural University, Beijing 100193, China.

Received: 23 February 2021 Accepted: 18 May 2021

Published online: 25 May 2021

\section{References}

Adhikary S, Naskar MK, Biswas B (2021) Seed priming -one small step for farmer, one giant leap for food security: I application and exploration. J Pharmacogn Phytochem 10(1):409-412. https://doi.org/10.22271/phyto. 2021.v10.i1f. 13340

Akhtar MS, Siddiqui ZA (2008) Arbuscular mycorrhizal fungi as potential bioprotectants against plant pathogens. In: Siddiqui ZA, Akhtar MS, Futai K (eds) Mycorrhizae: sustainable agriculture and forestry. Springer, Dordrecht, pp 61-98. https://doi.org/10.1007/978-1-4020-8770-7_3

Ali Q, Daud MK, Haider MZ, Ali S, Rizwan M, Aslam N, Noman A, lqbal N, Shahzad F, Deeba F, Ali I, Zhu SJ (2017) Seed priming by sodium nitroprusside improves salt tolerance in wheat (triticum aestivum L.) by enhancing physiological and biochemical parameters. Plant Physiol Bioch 119:50-58. https://doi.org/10.1016/j.plaphy.2017.08.010

Aliye N, Fininsa C, Hiskias Y (2008) Evaluation of rhizosphere bacterial antagonists for their potential to bioprotect potato (Solanum tuberosum) against bacterial wilt (Ralstonia solanacearum). Biol Control 47(3):282-288. https://doi.org/10.1016/j.biocontrol.2008.09.003

Babalola OO (2010) Beneficial bacteria of agricultural importance. Biotechnol Lett 32(11):1559-1570. https://doi.org/10.1007/s10529-010-0347-0

Bano A, Fatima M (2009) Salt tolerance in Zea mays (L.) following inoculation with Rhizobium and Pseudomonas. Biol Fertil Soils 45:405-413. https://doi. org/10.1007/s00374-008-0344-9

Bashan Y (1998) Inoculants for plant growth-promoting bacteria in agriculture. Biotechnol Adv 16(4):729-770. https://doi.org/10.1016/s0734-9750(98) 00003-2

Berendsen RL, Pieterse CMJ, Bakker PAHM (2012) The rhizosphere microbiome and plant health. Trends Plant Sci 17(8):1360-1385. https://doi.org/10. 1016/j.tplants.2012.04.001

Berg G, Grube M, Schloter M, Smalla K (2014) Unraveling the plant microbiome: looking back and future perspectives. Front Microbiol 5:1-7. https:// doi.org/10.3389/fmicb.2014.00148

Bhattacharyya PN, Jha DK (2012) Plant growth-promoting rhizobacteria (PGPR): emergence in agriculture. World J Microbiol Biotechnol 28:13271350. https://doi.org/10.1007/s11274-011-0979-9

Bohnert HJ, Sheveleva E (1998) Plant stress adaptations-making metabolism move. Curr Opin Plant Biol 1(3):267-274. https://doi.org/10.1016/s13695266(98)80115-5

Borrelli GM, Fragasso M, Nigro F, Platani C, Papa R, Beleggia R, Trono D (2018) Analysis of metabolic and mineral changes in response to salt stress in durum wheat (Triticum turgidum ssp. durum) genotypes, which differ in salinity tolerance. Plant Physiol Biochem 133:57-70. https://doi.org/10. 1016/j.plaphy.2018.10.025 
Chen GX, Asada K (1992) Inactivation of ascorbate peroxidase by thiols requires hydrogen peroxide. Plant Cell Physiol 33:117-123. https://doi. org/10.1093/oxfordjournals.pcp.a078229

Colla G, Rouphael Y, Mattia DE, El-Nakhel C, Cardarelli M (2015) Co-inoculation of Glomus intraradices and Trichoderma atroviride acts as a biostimulant to promote growth, yield and nutrient uptake of vegetable crops. J Sci Food Agric 95(8):1706-1715. https://doi.org/10.1002/jsfa.6875

Costa-Gutierrez SB, Lami MJ, Santo MCC, Zenoff AM, Vincent PA, MolinaHenares MA, Espinosa-Urgel M, de Cristobal RE (2020) Plant growth promotion by Pseudomonas putida KT2440 under saline stress: role of eptA. Appl Microbiol Biot 104:4577-4592. https://doi.org/10.1007/ s00253-020-10516-z

Deinlein U, Stephan AB, Horie T, Luo W, Xu G, Schroeder JI (2014) Plant salttolerance mechanisms. Trends Plant Sci 19(6):371-379. https://doi.org/10. 1016/j.tplants.2014.02.001

dos Santos Araújo G, de Oliveira P-M, de Paiva Pinheiro SK, de Castro ME, de Sousa LL, Camelo Marques E, de Carvalho HH, Gomes-Filho E (2021) $\mathrm{H}_{2} \mathrm{O}_{2}$ priming promotes salt tolerance in maize by protecting chloroplasts ultrastructure and primary metabolites modulation. Plant Sci 303:110774. https://doi.org/10.1016/j.plantsci.2020.110774

du Jardin P (2015) Plant biostimulants: Definition, concept, main categories and regulation. Sci Hortic 196(30):3-14. https://doi.org/10.1016/j.scienta. 2015.09.021

Feng G, Zhang F, Li X, Tian CY, Tang C, Rengel Z (2002) Improved tolerance of maize plants to salt stress by arbuscular mycorrhiza is related to higher accumulation of soluble sugars in roots. Mycorrhiza 12(4):185-190. https://doi.org/10.1007/s00572-002-0170-0

Filippou P, Antoniou C, Fotopoulos V (2013a) The nitric oxide donor sodium nitroprusside regulates polyamine and proline metabolism in leaves of Medicago truncatula plants. Free Radical Bio Med 56:172-183. https://doi. org/10.1016/j.freeradbiomed.2012.09.037

Filippou P, Tanou G, Molassiotis A, Fotopoulos V (2013b) Plant acclimation to environmental stress using priming agents. Plant acclimation to environmental stress. Springer, New York, New York, NY, pp 1-27. https://doi.org/ 10.1007/978-1-4614-5001-6_1

Gandonou CB, Bada F, Abrini J, Skali-Senhaji N (2012) Free proline, soluble sugars and soluble proteins concentration as affected by salt stress in two sugarcane (Saccharum sp.) cultivars differing in their salt tolerance. Int J Biol Chem Sci 5(6):2441-2453. https://doi.org/10.4314/ijbcs.v5i6.23

Gangola MP, Ramadoss BR (2018) Sugars play a critical role in abiotic stress tolerance in plants. Biochemical, physiological and molecular avenues for combating abiotic stress tolerance in plants. Elsevier, pp 17-38. https:// doi.org/10.1016/B978-0-12-813066-7.00002-4

Ghahfarokhi MG, Mansurifar S, Taghizadeh-Mehrjardi R, Saeidi M, Jamshidi AM, Ghasemi E (2015) Effects of drought stress and rewatering on antioxidant systems and relative water content in different growth stages of maize (Zea mays L.) hybrids. Arch Agron Soil Sci 61(4):493-506. https://doi.org/ 10.1080/03650340.2014.943198

Gong F, Yang L, Tai F, Hu X, Wang W (2014) "Omics" of maize stress response for sustainable food production: opportunities and challenges. OMICS 18(12):714-732. https://doi.org/10.1089/omi.2014.0125

Hayat R, Ali S, Amara U, Khalid R, Ahmed I (2010) Soil beneficial bacteria and their role in plant growth promotion: a review. Ann Microbiol 60(4):579_ 598. https://doi.org/10.1007/s13213-010-0117-1

Hoshida H, Tanaka Y, Hibino T, Hayashi Y, Tanaka A, Takabe T, Takabe T (2000) Enhanced tolerance to salt stress in transgenic rice that overexpresses chloroplast glutamine synthetase. Plant Mol Biol 43:103-111. https://doi. org/10.1023/A:1006408712416

Huang P, He L, Abbas A, Hussain S, Saqib M (2021) Seed priming with sorghum water extract improves the performance of camelina (camelina sativa (L.) crantz.) under salt stress. Plants 10(4):749. https://doi.org/10.3390/plant s10040749

Hyodo K, Suzuki N, Mise K, Okuno T (2017) Roles of superoxide anion and hydrogen peroxide during replication of two unrelated plant RNA viruses in Nicotiana benthamiana. Plant Signal Behav 12(6):e1338223. https://doi. org/10.1080/15592324.2017.1338223

Institute SAS (1999) SAS procedures guide; version 6. SAS/STAT Institute Inc., Cary, NC

ISTA (2007) Handbook on moisture determination. International Seed Testing Association, Bassersdorf
Ji SH, Gururani MA, Chun SC (2014) Isolation and characterization of plant growth promoting endophytic diazotrophic bacteria from Korean rice cultivars. Microbiol Res 169(1):83-98. https://doi.org/10.1016/j.micres. 2013.06.003

Jiang XW, Li HQ, Wei YJ, Song XY, Wang JH (2016) Seed biomechanical monitoring: A new method to test maize (Zea mays) seed vigour. Seed Sci Technol 44(2):382-392. https://doi.org/10.15258/sst.2016.44.2.10

Jisha KC, Puthur JT (2016) Seed priming with BABA ( $\beta$-amino butyric acid): a cost-effective method of abiotic stress tolerance in Vigna radiate (L.) Wilczek. Protoplasma 253(2):277-289. https://doi.org/10.1007/ s00709-015-0804-7

Jisha KC, Vijayakumari K, Puthur JT (2013) Seed priming for abiotic stress tolerance: an overview. Acta Physiol Plant 35(5):1381-1396. https://doi. org/10.1007/s11738-012-1186-5

Kishor PBK, Sreenivasulu N (2014) Is proline accumulation per se correlated with stress tolerance or is proline homeostasis a more critical issue? Plant Cell Environ 37(2):300-311. https://doi.org/10.1111/pce.12157

Li HQ, Jiang XW (2017) Inoculation with plant growth-promoting bacteria (PGPR) improves salt tolerance of maize seedling. Russ J Plant Physiol 64(2):235-241. https://doi.org/10.1134/S1021443717020078

Li HQ, Zhang LL, Jiang XW, Liu QZ (2015) Allelopathic effects of phenolic acids on the growth and physiological characteristics of strawberry plants. Allelopathy J 35(1):61-75

Liu X, Li X, Li Y, Li R, Xie Z (2017) Plant growth promotion properties of bacterial strains isolated from the rhizosphere of the Jerusalem artichoke (Helianthus tuberosus L.) adapted to saline-alkaline soils and their effect on wheat growth. Can J Microbiol 63(3):228-237. https://doi.org/10. 1139/cjm-2016-0511

Li HQ, Yue HW, Li L, Su CF, Zhang XW, Liu J, Yu ZY, Zhao GW, Song XY, Wang $J H$, Jiang XW (2019a) A comparative analysis of the hybrid maize (Zea mays L.) seed quality in China from 2013 to 2018. Agronomy 9(10):625. https://doi.org/10.3390/agronomy9100625

Li HQ, Zhao YM, Jiang XW (2019b) Seed soaking with Bacillus sp. strain HX-2 alleviates negative effects of drought stress on maize seedlings. Chil J Agr Res 79(3):396-404. https://doi.org/10.4067/S0718-5839201900 0300396

Li X, Sun P, Zhang Y, Jin C, Guan C (2020) A novel PGPR strain Kocuria rhizophila $Y 1$ enhances salt stress tolerance in maize by regulating phytohormone levels, nutrient acquisition, redox potential, ion homeostasis, photosynthetic capacity and stress-responsive genes expression. Environ Exp Bot 174:104023. https://doi.org/10.1016/j. envexpbot.2020.104023

Maach M, Akodad M, Moumen A, Skalli A, Baghour M (2021) Bio-regulators: silicon, salicylic acid, ascorbic acid improve salt tolerance in cucumber. Pharmacogn Rev 1(1):1-7. https://doi.org/10.11648/j.reviews.20210101. 11

Mahajan S, Tuteja N (2005) Cold, salinity and drought stresses: an overview. Arch Biochemand Biophys 444(2):139-158. https://doi.org/10.1016/j.abb. 2005.10.018

Meena VS, Meena SK, Verma JP, Kumar A, Aeron A, Mishra PK, Bisht JK, Pattanayak A, Naveed M, Dotaniya ML (2017) Plant beneficial rhizospheric microorganism (PBRM) strategies to improve nutrients use efficiency: a review. Ecol Eng 107:8-32. https://doi.org/10.1016/j.ecoleng.2017.06.058

Moeinzadeh A, Sharif-Zadeh F, Ahmadzadeh M, Tajabadi FH (2010) Biopriming of sunflower (Helianthus annuus L.) seed with Pseudomonas fluorescens for improvement of seed invigoration and seedling growth. Aust J Crop Sci 4(7):564-570. https://doi.org/10.2134/agronj2010.0141

Mohamed HI, Gomaa EZ (2012) Effect of plant growth promoting Bacillus subtilis and Pseudomonas fluorescens on growth and pigment composition of radish plants (Raphanus sativus) under $\mathrm{NaCl}$ stress. Photosynthetica 50(2):263-272. https://doi.org/10.1007/s1 1099-012-0032-8

Mukherjee PK, Horwitz BA, Herrera-Estrella A, Schmoll M, Kenerley CM (2012) Trichoderma research in the genome era. Annu Rev Phytopathol 51(1):105-129. https://doi.org/10.1146/annurev-phyto-082712-102353

Mukhopadhyay R, Pan S (2012) Effect of Biopriming of Radish (Raphanus sativus) seed with some antagonistic isolates of Trichoderma. J Plant Protect Sci 4(2):46-50

Munns R (2002) Comparative physiology of salt and water stress. Plant Cell Environ 25(2):239-250. https://doi.org/10.1046/j.0016-8025.2001.00808.x

Munns R, Tester M (2008) Mechanisms of salinity tolerance. Annu Rev Plant Biol 59:651-681. https://doi.org/10.1146/annurev.arplant.59.032607.092911 
Nicolás C, Hermosa R, Rubio B, Mukherjee PK, Monte E (2014) Trichoderma genes in plants for stress tolerance-status and prospects. Plant Sci 228:71-78. https://doi.org/10.1016/j.plantsci.2014.03.005

Ogireddy SD, Paul S, Sarkar D, Rajput RS, Singh S, Parihar M, Parewa HP, Pal S, Singh HB, Rakshit R (2019) Trichoderma: a part of possible answer towards crop residue disposal. J Appl Nat Sci 11(2):516-523. https://doi. org/10.31018/jans.v11 i 2.2090

Panuccio MR, Chaabani S, Roula R, Muscolo A (2018) Bio-priming mitigates detrimental effects of salinity on maize improving antioxidant defense and preserving photosynthetic efficiency. Plant Physiol Bioch 132:465474. https://doi.org/10.1016/j.plaphy.2018.09.033

Parida AK, Das AB (2005) Salt tolerance and salinity effects on plants: a review. Ecotox Environ Safe 60(3):324-329. https://doi.org/10.1016/j.ecoenv.2004. 06.010

Paul D, Lade H (2014) Plant-growth-promoting rhizobacteria to improve crop growth in saline soils: a review. Agron Sustain Dev 34(4):737-752. https:// doi.org/10.1007/s13593-014-0233-6

Philippot L, Raaijmakers JM, Lemanceau P, van der Putten WH (2013) Going back to the roots: the microbial ecology of the rhizosphere. Nat Rev Microbiol 11(11):789-799. https://doi.org/10.1038/nrmicro3109

Porcel R, Aroca R, Ruiz-Lozano JM (2012) Salinity stress alleviation using arbuscular mycorrhizal fungi: a review. Agron Sustain Dev 32(1):181-200. https://doi.org/10.1093/aob/mcp251

Rafiq K, Akram MS, Shahid M, Oaisar U, Rashid N (2020) Enhancement of salt tolerance in maize (Zea mays L.) using locally isolated Bacillus sp. SR-2-1/1. Biologia 75:1425-1436. https://doi.org/10.2478/s11756-020-00435-9

Rajkumar M, Ae N, Prasad MNV, Freitas H (2010) Potential of siderophoreproducing bacteria for improving heavy metal phytoextraction. Trends Biotechnol 28(3):142-149. https://doi.org/10.1016/j.tibtech.2009.12.002

Rajkumar M, Sandhya S, Prasad MNV, Freitas H (2012) Perspectives of plantassociated microbes in heavy metal phytoremediation. Biotechnol Adv 30(6):1562-1574. https://doi.org/10.1016/j.biotechadv.2012.04.01

Rakshit A, Sunita K, Pal S, Singh A, Singh HB (2015) Bio-priming mediated nutrient use efficiency of crop species. In: Rakshit A, Singh HB, Sen A (eds) Nutrient use efficiency: from basics to advances. Springer, New Delhi, pp 181-191. https://doi.org/10.1007/978-81-322-2169-2_12

Ramadoss D, Lakkineni VK, Bose P, Ali S, Annapurna K (2013) Mitigation of salt stress in wheat seedlings by halotolerant bacteria isolated from saline habitats. Springerplus 2(1):6. https://doi.org/10.1186/2193-1801-2-6

Rhaman MS, Imran S, Rauf F, Khatun M, Baskin CC, Murata Y, Hasanuzzaman M (2020a) Seed priming with phytohormones: an effective approach for the mitigation of abiotic stress. Plants 10(1):37. https://doi.org/10.3390/plant s10010037

Rhaman MS, Rauf F, Tania SS, Khatun M (2020b) Seed priming methods: application in field crops and future perspectives. Asian J Res Crop Sci 5(2):8-19. https://doi.org/10.9734/AJRCS/2020/v5i230091

Rojas-Tapias D, Moreno-Galván A, Pardo-Díaz S, Obando M, Rivera D, Bonilla $R$ (2012) Effect of inoculation with plant growth-promoting bacteria (PGPB) on amelioration of saline stress in maize (Zea mays). Appl Soil Ecol 61:264-272. https://doi.org/10.1016/j.apsoil.2012.01.006

Selvakumar G, Kim K, Shagol CC, Joe MM, Sa T (2017) Spore associated bacteria of arbuscular mycorrhizal fungi improve maize tolerance to salinity by reducing ethylene stress level. Plant Growth Regul 81(1):159-165. https:// doi.org/10.1007/s10725-016-0184-9

Shoresh M, Harman GE, Mastouri F (2010) Induced systemic resistance and plant responses to fungal biocontrol agents. Annu Rev Phytopathol 48(1):21-43. https://doi.org/10.1146/annurev-phyto-073009-114450

Sureshrao KS, Pradeeprao KT, Dnyanobarao GS, Agrawal T, Kotasthane AS (2016) Root growth stimulation in rice (Oryza sativa L.) by seed biopriming with Trichoderma sp. Appl Biol Res 18(1):30-38. https://doi.org/ 10.5958/0974-4517.2016.00005.7

Tao GC, Tian SJ, Cai MY, Xie GH (2008) Phosphate-solubilizing and -mineralizing abilities of bacteria isolated from soils. Pedosphere 18(4):515-523. https:// doi.org/10.1016/S1002-0160(08)60042-9

Teixeira J, Pereira S (2007) High salinity and drought act on an organ-dependent manner on potato glutamine synthetase expression and accumulation. Environ Exp Bot 60(1):121-126. https://doi.org/10.1016/j.envexpbot. 2006.09.003

Tester M, Davenport R (2003) $\mathrm{Na}^{+}$tolerance and $\mathrm{Na}^{+}$transport in higher plants. Ann Bot 91:503-527. https://doi.org/10.1093/aob/mcg058

Tilman D, Balzer C, Hill J, Befort BL (2011) Global food demand and the sustainable intensification of agriculture. PNAS 108(50):20260-20264. https:// doi.org/10.2307/23060109

Upadhyay SK, Singh JS, Saxena AK, Singh DP (2011) Impact of PGPR inoculation on growth and antioxidant status of wheat under saline conditions. Plant Biol 14(4):605-611. https://doi.org/10.1111/j.1438-8677.2011. 00533.x

van Zelm E, Zhang YX, Testerink C (2020) Salt tolerance mechanisms of plants. Annu Rev Plant Biol 71:24.1-24.31. https://doi.org/10.1146/annurev-arpla nt-050718-100005

Woo SL, Pepe O (2018) Microbial consortia: promising probiotics as plant biostimulants for sustainable agriculture. Front Plant Sci 9:1801. https:// doi.org/10.3389/fpls.2018.01801

Yu ZP, Duan XB, Luo L, Dai SJ, Ding ZJ, Xia GM (2020) How plant hormones mediate salt stress responses. Trends Plant Sci 25(11):1117-1130. https:// doi.org/10.1016/j.tplants.2020.06.008

Zhang X, Liu L, Chen B, Qin Z, Xiao Y, Zhang Y, Yao R, Liu H, Yang H (2019) Progress in understanding the physiological and molecular responses of populus to salt stress. Int J Mol Sci. 20(6):1312. https://doi.org/10.3390/ ijms20061312

Zhu JK (2001) Plant salt tolerance. Trends Plant Sci 6:66-71. https://doi.org/10. 1016/S1360-1385(00)01838-0

Zhu XC, Song FB, Xu HW (2010) Influence of arbuscular mycorrhiza on lipid peroxidation and antioxidant enzyme activity of maize plants under temperature stress. Mycorrhiza 20:325-332. https://doi.org/10.1007/ s00572-009-0285-7

\section{Publisher's Note}

Springer Nature remains neutral with regard to jurisdictional claims in published maps and institutional affiliations.

\section{Submit your manuscript to a SpringerOpen ${ }^{\circ}$ journal and benefit from:}

- Convenient online submission

- Rigorous peer review

- Open access: articles freely available online

- High visibility within the field

- Retaining the copyright to your article

Submit your next manuscript at springeropen.com 